\title{
Internet-Based Psychodynamic versus Cognitive Behavioral Guided Self-Help for Generalized Anxiety Disorder: A Randomized Controlled Trial
}

\author{
Gerhard Andersson $^{\text {b, c }}$ Björn Paxling ${ }^{a, b}$ Pie Roch-Norlund ${ }^{d} \quad$ Gunnar Östman $^{d}$ \\ Anna Norgren $^{d}$ Jonas Almlöv ${ }^{b}$ Lisa Georén ${ }^{e} \quad$ Elisabeth Breitholtz ${ }^{d}$ \\ Mats Dahlin ${ }^{f}$ Pim Cuijpers $^{\mathrm{a}}$ Per Carlbring ${ }^{g}$ Farrell Silverberg $^{\mathrm{h}}$ \\ a Department of Clinical Psychology and EMGO Institute, Vrije Universiteit, Amsterdam, The Netherlands; \\ ${ }^{b}$ Department of Behavioural Sciences and Learning, Swedish Institute for Disability Research, Linköping University, \\ Linköping, ' Division of Psychiatry, Department of Clinical Neuroscience, Karolinska Institutet, and ${ }^{\mathrm{d} D e p a r t m e n t}$ \\ of Psychology, Stockholm University, Stockholm, e'Department of Psychology, Uppsala University, Uppsala,

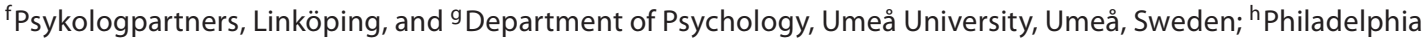 \\ School of Psychoanalysis and Private Practice, Philadelphia, Pa., USA
}

\section{Key Words}

Guided self-help - Generalized anxiety disorder •

Psychodynamic therapy · Cognitive behavior therapy

\begin{abstract}
Background: Guided Internet-based cognitive behavior therapy (ICBT) has been tested in many trials and found to be effective in the treatment of anxiety and mood disorders. Generalized anxiety disorder (GAD) has also been treated with ICBT, but there are no controlled trials on guided Internet-based psychodynamic treatment (IPDT). Since there is preliminary support for psychodynamic treatment for GAD, we decided to test if a psychodynamically informed self-help treatment could be delivered via the Internet. The aim of the study was to investigate the efficacy of IPDT for GAD and to compare against ICBT and a waiting list control group. Method: A randomized controlled superiority trial with individuals diagnosed with GAD comparing guided ICBT $(n=27)$ and IPDT $(n=27)$ against a no treatment waiting list control group $(n=27)$. The primary outcome measure was the Penn State Worry Questionnaire. Results: While there were no sig-
\end{abstract}

nificant between-group differences immediately after treatment on the main outcome measure, both IPDT and ICBT resulted in improvements with moderate to large withingroup effect sizes at 3 and 18 months follow-up on the primary measure in the completer analyses. The differences against the control group, although smaller, were still significant for both PDT and CBT when conforming to the criteria of clinically significant improvement. The active treatments did not differ significantly. There was a significant group by time interaction regarding GAD symptoms, but not immediately after treatment. Conclusions: IPDT and ICBT both led to modest symptom reduction in GAD, and more research is needed.

Copyright $\odot 2012$ S. Karger AG, Basel

\section{Introduction}

Generalized anxiety disorder (GAD) is a common and persistent disorder characterized by intense and uncontrollable worry [1]. Even if symptom of worry in GAD can be situationally aggravated, such worry is not explained

\section{KARGER}

Fax +4161306 1234 E-Mail karger@karger.ch www.karger.com
(C) 2012 S. Karger AG, Basel

0033-3190/12/0816-0344\$38.00/0

Accessible online at:

www.karger.com/pps
Gerhard Andersson, $\mathrm{PhD}$

Department of Behavioural Sciences and Learning

Linköping University

SE-58183 Linköping (Sweden)

E-Mail Gerhard.Andersson@liu.se 
by reactions to recent stressful events. GAD is often comorbid with other anxiety and mood disorders and the lifetime prevalence ranges between 4.3 and 5.9\% [2]. Different treatment options exist [2], and cognitive behavior therapy (CBT) is the psychological treatment approach that has received the most empirical support in terms of the number of trials conducted [3]. Additionally, there are some indications that psychodynamic psychotherapy (PDT) can work well for patients with GAD $[4,5]$. Recently, CBT has been transposed for delivery over the Internet [6] and a few randomized controlled trials have investigated the effects of Internet-based CBT (ICBT) for GAD [7-9]. There are now numerous controlled trials on guided ICBT for anxiety disorders [10], but no prior studies on Internet-based PDT (IPDT). The present study aimed at investigating the effects of a guided IPDT and CBT for GAD. We hypothesized that participants receiving IPDT, relative to those in a waiting list control condition, would show a statistically significant reduction of worry and depressive symptoms and an improvement in quality of life. In addition, we added a comparison group who received ICBT. We expected similar outcomes for IPDT and CBT on measures of worry [5].

\section{Methods}

\section{Design}

This was a superiority trial where two active treatments were compared with a waiting list group with unrestricted randomization in a 1:1:1 ratio, conducted in Sweden. Participants in the control condition were offered ICBT after the 3-month follow-up assessment.

\section{Participants and Recruitment}

The study protocol was approved by the regional ethics committee. Participants were self-recruited using either a website (www.studie.nu) which serves to recruit participants to a variety of studies or via an advertisement in a major Swedish newspaper. The participants received an e-mail with information about the treatment and screening procedures, and they then entered their personal information, answered a battery of web-administered questionnaires for screening purposes, and finally signed and posted a letter of informed consent that was needed to enter the study. Those who fulfilled the initial inclusion criteria on the screening questionnaires were then interviewed via telephone using the Structured Clinical Interview for DSM-IV Axis I Disorders research version - SCID-I [11], which has been found to generate reliable diagnoses when administered over the telephone [12]. To be eligible for inclusion, potential participants had to meet the following criteria: (a) fulfill the diagnostic criteria for GAD according to DSM-IV; (b) be at least 18 years old; (c) have access to the Internet; (d) have good knowledge of the Swedish language; (e) if taking prescribed medication for anxiety or depression, the duration had to be at least 12 weeks, and the participant had to be on a stable dosage for at least 6 weeks (and such participants were instructed not to change medication and/or dosage during the trial); (f) not be in any other psychological treatment during the study period, and (g) not be severely depressed or suicidal as assessed by self-report and telephone interview. A psychiatrist served as consultant during the entire trial. No incentives were given for participation.

\section{Outcome Measures}

Primary Outcome Measure. The primary outcome measure in the trial was the Penn State Worry Questionnaire (PSWQ) [13]. The PSWQ has 16 items and is designed to capture the generality, excessiveness and uncontrollability of pathological worry. The PSWQ has a test-retest reliability between 0.74 and 0.93 (2-10 weeks) and Cronbach's alpha between 0.86 and 0.93 [14].

Secondary Outcome Measures. We additionally included the Generalized Anxiety Disorder Questionnaire IV (GAD-Q-IV) [15] for measuring GAD symptoms. GAD-Q-IV has a test-retest reliability of 0.81 and Cronbach's alpha 0.84 [16]. A third measure was the Montgomery Åsberg Depression Rating Scale - Self rated (MADRS-S) [17], which was used to screen for the exclusion criteria of severe depression and suicidal tendencies. The test-retest reliability of MADRS-S is between 0.80 and 0.94 , and Cronbach's alpha varies between 0.82 and 0.90 [18]. The Quality of Life Inventory (QOLI) [19] was used to measure life quality in 16 domains. The QOLI has test-retest reliability of $r=0.92$ and a Cronbach's alpha of 0.81 [19]. The State-Trait Anxiety Inventory (STAI state and trait versions) [20], the Beck Depression Inventory (BDI-II) [21], and the Beck Anxiety Inventory (BAI) [22] were used to measure depressed mood and anxiety symptoms. Psychometric properties of these two measures are good with a test-retest reliability of $r=0.71$ and Cronbach's alpha $=0.86$ for the STAI scales [20], and equally high for the BDI including online administration [23]. However, it should be noted that the three latter questionnaires were not administered in the 18-month follow-up with the rationale of endeavoring to decrease the questionnaire completion burden at that point.

Clinician-Administered Measures. Psychiatric diagnoses were assessed using the SCID-I [11]. Global functioning was measured by the Clinical Global Improvement Scale (CGI), a 7-item interview list for assessing clinical improvement [24]. Raters received training and had to complete approved test interviews before the trial

\section{Procedure}

Assessment Points and Randomization. A telephone interview was conducted before and after the treatment, as well as at the 18-month follow-up. The interview included the administration of the SCID-I [11]. Those participants assigned to the waiting list control group were told that they were being placed on a waiting list and would receive treatment after a 3 -month waiting period. At posttreatment and follow-up, an estimation of the degree of global improvement for each participant was calculated using the CGI improvement scale [24]. After the treatment period, the interviewers were blinded concerning participant status and allocation (given that the posttreatment interviewers did not have access to information about the participants). In addition, participants were asked not to reveal whether they had received treatment. 
Three months after the end of the initial treatment period, all self-report measures were administered again and, subsequently, the waiting list control group received the CBT treatment. An 18-month follow-up was conducted with four self-report inventories and a blinded telephone interview carried out by a trained interviewer (who had not served as therapist nor previously worked in the project). Questions regarding change in medication and/or additional treatment seeking were asked at post-test and at follow-up.

The randomization procedure was managed by an external administrator who was not otherwise involved in the study. A true random number service (www.random.org) was used to ensure complete randomness. Randomization was done after inclusion wherein participants were randomized to the three groups with no stratification.

\section{Interventions}

Internet-Based Psychodynamic Therapy. The IPDT used in this study was based on the method detailed in the book Make the Leap [25], which was translated into Swedish and adapted, with the assistance of the book's author, to a format suitable for an Internetdelivered self-help program. Make the Leap is a self-help book based on psychodynamic principles. The reader was guided through a program called SUBGAP, which stands for (1) Seeing unconscious patterns that contribute to emotional difficulties, (2) Understanding these patterns, (3) Breaking such unhelpful patterns, and (4) Guarding against patterns and/or relapses in the future. The treatment consisted of 8 text-based treatment modules/ chapters delivered on a weekly basis. The modules varied in length between 11 and 17 pages each, making the entire treatment consist of 111 pages of material for the participants to read. Briefly, the treatment modules covered (1) Introduction; (2) Systematic practice in discovering one's own unconscious patterns; (3) Understanding patterns from an historical perspective of looking at one's life; (4) Different methods that can be used to break the patterns that one discovers; (5) Minimizing the risk of falling back into one's old and unproductive patterns; (6) Applying the knowledge one gains about patterns with a focus on solving the dilemmas of working life; (7) Applying knowledge about patterns with a focus on improving personal relationships, and (8) The relationship between unconscious patterns and anxiety/worry. Each module ended with a series of discussion themes about which the participants were encouraged to write and send such writings to the guiding therapist using a confidentiality-maintaining encrypted communication platform. The main focus for the therapists was to guide the participants through the self-help program by giving feedback and encouragement in response to the weekly communications. No formal homework assignments were given. Supervision was provided by a certified Training and Supervising Psychoanalyst from a post-degree psychoanalytic institute program. Supervision was conducted via two-way videoconference over the Internet. In total, there were seven supervision sessions, each approximately $90 \mathrm{~min}$ in length. Treatment support for participants in this arm of the study was provided by 3 therapists who were in their final year of a 5-year clinical psychology program and by one licensed psychologist. Each was responsible for 6-7 participants. All therapists had been trained in psychodynamic treatment, including supervised case experience conducting psychodynamic therapy. They also identified themselves as having a psychodynamic orientation. The mean therapist time devoted to each client during the entire treatment period was $113 \mathrm{~min}(\mathrm{SD}=41)$. Feedback was given as soon as possible, most often within $24 \mathrm{~h}$. Except for the weekly online treatment contacts and diagnostic procedures, no other contact took place between the therapists and participants.

Internet-Based Cognitive Behavioral Therapy. The ICBT employed in this study utilized the treatment protocol developed by Paxling et al. [7]. The treatment consisted of 8 text-based treatment modules delivered on a weekly basis for 8 weeks. The treatment modules covered (1) Introduction to GAD and the treatment (psychoeducation); (2) Step 1 of applied relaxation [26]; (3) Step 2 of applied relaxation, and worry time; (4) Step 3 of applied relaxation, and cognitive restructuring; (5) Step 4 of applied relaxation, cognitive distancing, and problem solving; (6) Step 5 of applied relaxation, and worry exposure; (7) Step 6 of applied relaxation, interpersonal problem solving [27], and sleep management, and (8) Relapse prevention and maintenance of progress. In the different steps of applied relaxation, participants first learn the relaxation technique in 15-min sessions (step 1); then, the duration of the relaxation is progressively shortened to 5-7 $\mathrm{min}$ (step 2), 2-3 min (step 3), 60-90 s (step 4) and finally to 20-30 s (step 5) before the relaxation is applied in everyday life (step 6). Audio files with instructions for applied relaxation were available as downloads on the project website. All treatment modules were accompanied by homework assignments that participants submitted to the therapists on a weekly basis. Homework assignments had to be completed before a particular participant could start with the next module. The main focus for the therapists was to guide the participants through the self-help program. Each week the participants sent in reports on their progress that included the option of including questions that directly addressed the therapist. Feedback was given as soon as possible, most often within $24 \mathrm{~h}$. Except for the weekly online treatment contact and diagnostic procedures, no other contact took place between the therapists and participants. In total, 5 therapists provided the treatment for this group. Two were licensed psychologists who had previous experience guiding Internet treatment for GAD, and 3 were psychology students in their final year. Each therapist was responsible for 4-6 participants. All therapists had received training in CBT and identified themselves as having a CBT orientation. The therapists were supervised by a senior researcher and licensed CBT therapist. In total, four supervision sessions were given of approximately 90 min each. Feedback from the therapist was provided to the participants on a weekly basis in association with the homework assignments. In addition, occasional reminders were sent. The mean therapist time devoted to each client during the overall treatment period was $92 \min (\mathrm{SD}=61)$.

\section{Statistical Analysis}

Statistical analyses were conducted using the PASW version 18.0 (SPSS Inc., Chicago, Ill., USA).

In order to account for dropouts without assuming that the first measurement was stable (i.e. the last observation carried forward assumption), we used a mixed effects models approach with full information maximum likelihood estimation [28]. Mixed effect models are able to accommodate missing data and integrate time-varying factors. Mixed model analyses have been recommended as a way to handle intention-to-treat data [29]. A firstorder autoregressive covariance structure was used for the immediate effects, and an unstructured covariance matrix structure was employed for the long-term follow-up data. 
Fig. 1. Flow chart of participants through

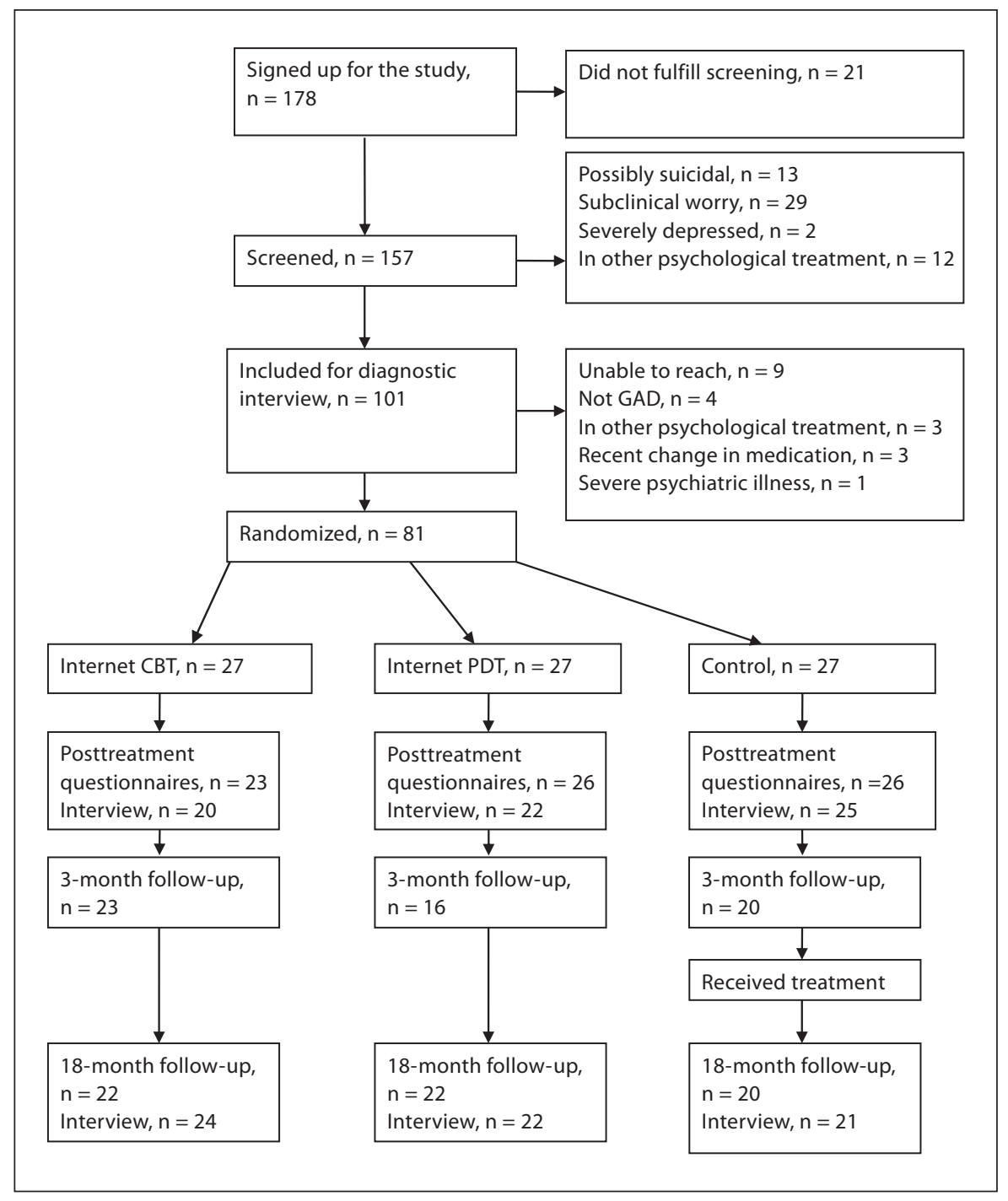
the study.

Effect sizes are presented as Cohen's d [30], defined as the difference between the means of the two groups divided by the pooled standard deviation. Within-group effect sizes are based on the pooled SDs; between-group effect sizes are based on the posttreatment means, and all effect sizes are based on collected completer's data (e.g. rather than with replacements).

$\chi^{2}$ was used to test for differences between the groups on categorical outcomes. To be defined as clinically recovered, a participant had to fulfill the criterion for reliable change index and had to have a posttreatment score of at least 2 standard deviations below the group mean at pretreatment [31].

We made a power calculation based on the comparison between the active treatments and the waiting list control group. In order to have $80 \%$ power to detect an effect size of $d=0.80$, the study was sufficiently powered (alpha $=0.05)$. However, the comparison between the two active treatments was not sufficiently powered given the large samples needed to test for non-inferiority [32].

Internet-Based PDT versus CBT for

Generalized Anxiety Disorder

\section{Results}

\section{Patient Characteristics, Attrition and Adherence}

Characteristics of the included participants are presented in table 1 . The three groups did not differ on any pretreatment characteristic. In table 2 , we present data on comorbidity. Loss of data and participant flow are presented in figure 1. The average number of completed modules in IPDT was $5.9(\mathrm{SD}=2.2)$, and in ICBT it was $5.1(\mathrm{SD}=2.5)$.

\section{Treatment Effectiveness - Primary Outcome Measure (PSWQ)}

Observed means and Cohen's d within-group effect sizes are presented in table 3 (for estimated means see on-

Psychother Psychosom 2012;81:344-355 
Table 1. Characteristics of the participants before treatment

\begin{tabular}{|c|c|c|c|c|}
\hline Variable & & $\begin{array}{l}\text { ICBT } \\
(n=27)\end{array}$ & $\begin{array}{l}\text { IPDT } \\
(n=27)\end{array}$ & $\begin{array}{l}\text { Wait-list control } \\
(\mathrm{n}=27)\end{array}$ \\
\hline \multirow[t]{2}{*}{ Gender } & Women & 20 & 21 & 21 \\
\hline & Men & 7 & 6 & 6 \\
\hline \multirow[t]{2}{*}{ Age } & Mean $\pm S D$ & $44.4 \pm 12.8$ & $36.4 \pm 9.7$ & $39.6 \pm 13.7$ \\
\hline & Range & $22-66$ & $24-60$ & $19-65$ \\
\hline \multirow[t]{2}{*}{ GAD } & Duration, years, mean $\pm S D$ & $20.5 \pm 11.6$ & $19.3 \pm 12.3$ & $19.6 \pm 16.5$ \\
\hline & Age at onset, years, mean $\pm S D$ & $23.8 \pm 14.1$ & $17.2 \pm 11.5$ & $20.0 \pm 13.1$ \\
\hline \multirow[t]{3}{*}{ Occupational status } & Working & 14 & 17 & 19 \\
\hline & Sick leave, part- or full-time & 10 & 8 & 4 \\
\hline & Other & 3 & 2 & 4 \\
\hline \multirow{2}{*}{\multicolumn{2}{|c|}{$\begin{array}{l}\text { Education after gymnasium } \\
\text { (e.g. university), \% }\end{array}$}} & & & \\
\hline & & 64.8 & 59.1 & 76.1 \\
\hline \multirow{8}{*}{ Civil status } & Married/relationship with children & 13 & 12 & 12 \\
\hline & Married/relationship without children & 5 & 5 & 3 \\
\hline & In relationship, living apart & 2 & 1 & 1 \\
\hline & Single with children & 3 & 2 & 1 \\
\hline & Single without children & 2 & 5 & 6 \\
\hline & Widow/widower & 1 & 1 & 1 \\
\hline & Living with parents & 0 & 0 & 2 \\
\hline & Other & 1 & 1 & 1 \\
\hline \multirow[t]{2}{*}{ Psychotherapy } & Previous & 19 & 21 & 15 \\
\hline & Never & 8 & 5 & 12 \\
\hline \multirow{3}{*}{$\begin{array}{l}\text { Medication for psychiatric } \\
\text { illness }\end{array}$} & Ongoing & 8 & 12 & 6 \\
\hline & Previous & 13 & 8 & 11 \\
\hline & Never & 6 & 6 & 10 \\
\hline
\end{tabular}

Table 2. Axis I comorbidity according to the DSM-IV for each group

\begin{tabular}{|c|c|c|c|c|c|c|}
\hline & \multicolumn{2}{|c|}{ ICBT $(\mathrm{n}=27)$} & \multicolumn{2}{|c|}{ IPDT $(\mathrm{n}=27)$} & \multicolumn{2}{|c|}{ Wait-list control $(\mathrm{n}=27)$} \\
\hline & participants & $\%$ & participants & $\%$ & participants & $\%$ \\
\hline Social phobia & 6 & 22.2 & 7 & 25.9 & 5 & 18.5 \\
\hline Panic disorder & 7 & 25.9 & 3 & 11.1 & 6 & 22.2 \\
\hline OCD & 0 & 0.0 & 2 & 7.4 & 1 & 3.7 \\
\hline Current depressive episode & 10 & 37.0 & 4 & 14.8 & 5 & 18.5 \\
\hline Previous depressive episode & 16 & 59.3 & 12 & 44.4 & 12 & 44.4 \\
\hline$\geq 1$ other Axis 1 diagnosis & 16 & 59.3 & 13 & 48.1 & 14 & 51.9 \\
\hline
\end{tabular}

line table 1). Between-group effect sizes at posttreatment were small and insignificant. On the PSWQ, there was a moderate between-group effect size between IPDT and the control condition at 3 months $(\mathrm{d}=0.64 ; 95 \% \mathrm{CI}:-0.05$ to 1.30 ), and similarly for the ICBT versus control condition ( $\mathrm{d}=0.76$; 95\% CI: 0.10-1.33). The difference between the two treatments was small and statistically insignificant ( $\mathrm{d}=0.14 ; 95 \% \mathrm{CI}:-0.50$ to 0.78$)$ in favor of CBT. Data on the PSWQ are presented in figure 2 to display the relatively small magnitude of the changes.

When conforming to the criteria of clinically significant improvement as defined by Jacobson and Truax [31] 
Table 3. Means \pm SDs and within-group effect sizes (Cohen's d) including confidence intervals for primary and secondary outcome measures before treatment, after treatment and at 3-and 18-month follow-up

\begin{tabular}{|c|c|c|c|c|c|c|}
\hline & \multicolumn{2}{|c|}{ ICBT } & \multicolumn{2}{|c|}{ IPDT } & \multicolumn{2}{|c|}{ Wait-list control } \\
\hline & $\mathrm{n}$ & mean $\pm \mathrm{SD}$ & $\mathrm{n}$ & mean $\pm \mathrm{SD}$ & $\mathrm{n}$ & mean $\pm \mathrm{SD}$ \\
\hline \multicolumn{7}{|l|}{ PSWQ (16-80) } \\
\hline Before treatment & 27 & $67.89 \pm 6.19$ & 27 & $69.74 \pm 5.56$ & 27 & $68.52 \pm 6.24$ \\
\hline After treatment & 23 & $60.78 \pm 9.83$ & 26 & $61.88 \pm 7.73$ & 26 & $62.88 \pm 9.39$ \\
\hline 3-month follow-up & 23 & $56.48 \pm 12.17$ & 16 & $58.13 \pm 10.83$ & 20 & $64.05 \pm 7.81$ \\
\hline 18-month follow-up $(\mathrm{n}=22)$ & 22 & $50.23 \pm 11.82$ & 22 & $53.14 \pm 10.89$ & 20 & $53.10 \pm 10.70$ \\
\hline Cohen's d $\mathrm{d}^{1}(95 \% \mathrm{CI})$ & & $0.87(0.25-1.46)$ & & $1.16(0.56-1.73)$ & & $0.72(0.13-1.25)$ \\
\hline Cohen's d ${ }^{2}(95 \%$ CI) & & $1.18(0.53-1.78)$ & & $1.35(0.55-2.08)$ & & $0.64(-0.01$ to 1.26$)$ \\
\hline Cohen's d ${ }^{3}(95 \%$ CI) & & $1.88(1.14-2.55)$ & & $1.92(1.17-2.69)$ & & $1.76(1.00-2.75)$ \\
\hline \multicolumn{7}{|l|}{$G A D-Q-I V(0-12)$} \\
\hline Before treatment & 27 & $10.44 \pm 1.09$ & 27 & $10.95 \pm 1.14$ & 27 & $10.82 \pm 1.20$ \\
\hline After treatment & 23 & $8.53 \pm 2.37$ & 26 & $8.34 \pm 3.31$ & 26 & $8.52 \pm 3.70$ \\
\hline 3-month follow-up & 23 & $6.04 \pm 4.12$ & 16 & $5.51 \pm 3.70$ & 20 & $9.10 \pm 2.66$ \\
\hline 18-month follow-up & 22 & $5.82 \pm 1.19$ & 22 & $5.16 \pm 1.19$ & 20 & $5.04 \pm 1.35$ \\
\hline Cohen's d ${ }^{1}(95 \%$ CI) & & $1.04(0.40-1.63)$ & & $1.05(0.46-1.62)$ & & $0.84(0.26-1.39)$ \\
\hline Cohen's d ${ }^{2}(95 \%$ CI $)$ & & $1.46(0.79-2.08)$ & & $1.99(1.10-2.78)$ & & $0.83(0.17-1.46)$ \\
\hline Cohen's d ${ }^{3}(95 \% \mathrm{CI})$ & & $4.05(2.96-5.00)$ & & $4.97(3.70-6.06)$ & & $4.53(3.28-5.59)$ \\
\hline \multicolumn{7}{|l|}{$M A D R S-S(0-54)$} \\
\hline Before treatment & 27 & $22.30 \pm 6.52$ & 27 & $19.74 \pm 5.11$ & 27 & $21.41 \pm 5.99$ \\
\hline After treatment & 23 & $12.87 \pm 6.35$ & 26 & $16.12 \pm 8.93$ & 26 & $17.15 \pm 7.92$ \\
\hline 3-month follow-up & 23 & $14.91 \pm 8.72$ & 16 & $11.69 \pm 5.87$ & 20 & $16.35 \pm 7.61$ \\
\hline 18-month follow-up & 22 & $9.32 \pm 6.88$ & 22 & $15.36 \pm 10.48$ & 20 & $11.65 \pm 7.53$ \\
\hline Cohen's d ${ }^{1}(95 \%$ CI $)$ & & $1.47(0.79-2.09)$ & & $0.50(-0.06$ to 1.04$)$ & & $0.61(0.04-1.15)$ \\
\hline Cohen's d ${ }^{2}(95 \%$ CI) & & $0.96(0.33-1.55)$ & & $1.46(0.65-2.20)$ & & $0.74(0.08-1.36)$ \\
\hline Cohen's d ${ }^{3}(95 \%$ CI $)$ & & $1.94(1.19-2.61)$ & & $0.53(-0.08$ to 1.12$)$ & & $1.43(0.71-2.10)$ \\
\hline \multicolumn{7}{|l|}{ QOLI (-6 to 6) } \\
\hline Before treatment & 27 & $0.57 \pm 1.75$ & 27 & $0.80 \pm 1.54$ & 27 & $0.67 \pm 1.43$ \\
\hline After treatment & 23 & $1.64 \pm 1.50$ & 26 & $1.23 \pm 1.65$ & 26 & $1.00 \pm 1.56$ \\
\hline 3-month follow-up & 23 & $1.06 \pm 2.01$ & 16 & $2.01 \pm 1.35$ & 20 & $1.28 \pm 1.50$ \\
\hline 18-month follow-up & 22 & $1.62 \pm 2.00$ & 22 & $1.32 \pm 1.59$ & 20 & $1.63 \pm 1.32$ \\
\hline Cohen's d ${ }^{1}(95 \%$ CI $)$ & & $-0.66(-1.25$ to 0.05$)$ & & $-0.27(-0.81$ to 0.28$)$ & & $-0.22(-0.76$ to 0.33$)$ \\
\hline Cohen's d ${ }^{2}(95 \%$ CI $)$ & & $-0.26(-0.84$ to 0.32$)$ & & $-0.84(-1.54$ to 0.09$)$ & & $-0.42(-1.03$ to 0.22$)$ \\
\hline Cohen's d ${ }^{3}(95 \% \mathrm{CI})$ & & $-0.56(-1.14$ to 0.05$)$ & & $-0.33(-1.02$ to 0.37$)$ & & $-0.70(-1.32$ to 0.05$)$ \\
\hline \multicolumn{7}{|l|}{ STAI - state (20-80) } \\
\hline Before treatment & 27 & $63.11 \pm 9.45$ & 27 & $59.59 \pm 6.79$ & 27 & $61.63 \pm 9.06$ \\
\hline After treatment & 23 & $50.13 \pm 11.36$ & 26 & $50.27 \pm 9.52$ & 26 & $55.96 \pm 12.00$ \\
\hline 3-month follow-up & 23 & $52.22 \pm 13.43$ & 16 & $47.69 \pm 11.66$ & 20 & $56.90 \pm 9.41$ \\
\hline Cohen's d ${ }^{1}(95 \%$ CI $)$ & & $1.24(0.59-1.85)$ & & $1.13(0.53-1.69)$ & & $0.53(-0.03$ to 1.08$)$ \\
\hline Cohen's d ${ }^{2}(95 \% \mathrm{CI})$ & & $0.95(0.41-1.64)$ & & $1.25(0.46-1.97)$ & & $0.51(-0.13$ to 1.13$)$ \\
\hline \multicolumn{7}{|l|}{ STAI - trait (20-80) } \\
\hline Before treatment & 27 & $58.74 \pm 7.12$ & 27 & $59.96 \pm 5.85$ & 27 & $59.89 \pm 7.69$ \\
\hline After treatment & 23 & $50.17 \pm 8.34$ & 26 & $54.12 \pm 8.07$ & 26 & $55.00 \pm 8.90$ \\
\hline 3-month follow-up & 23 & $51.30 \pm 11.82$ & 16 & $48.13 \pm 9.54$ & 20 & $53.90 \pm 8.66$ \\
\hline Cohen’s d ${ }^{1}$ (95\% CI) & & $1.10(0.46-1.70)$ & & $0.83(0.25-1.38)$ & & $0.59(0.02-1.13)$ \\
\hline Cohen's d² (95\% CI) & & $0.76(0.15-1.35)$ & & $1.49(0.68-2.24)$ & & $0.73(0.08-1.36)$ \\
\hline
\end{tabular}


Table 3 (continued)

\begin{tabular}{|c|c|c|c|c|c|c|}
\hline & \multicolumn{2}{|c|}{ ICBT } & \multicolumn{2}{|c|}{ IPDT } & \multicolumn{2}{|c|}{ Wait-list control } \\
\hline & $\mathrm{n}$ & mean $\pm S D$ & $\mathrm{n}$ & mean $\pm \mathrm{SD}$ & $\mathrm{n}$ & mean $\pm \mathrm{SD}$ \\
\hline \multicolumn{7}{|l|}{$B A I(0-63)$} \\
\hline Before treatment & 27 & $24.30 \pm 9.10$ & 27 & $25.26 \pm 8.59$ & 27 & $23.70 \pm 10.61$ \\
\hline After treatment & 23 & $15.09 \pm 6.99$ & 26 & $15.88 \pm 8.87$ & 26 & $19.52 \pm 10.34$ \\
\hline 3-month follow-up & 23 & $16.65 \pm 12.32$ & 16 & $13.13 \pm 8.88$ & 20 & $19.30 \pm 11.67$ \\
\hline Cohen's d ${ }^{1}(95 \%$ CI) & & $1.14(0.49-1.74)$ & & $1.07(0.48-1.64)$ & & $0.40(-0.16$ to 0.94$)$ \\
\hline Cohen's d² (95\% CI) & & $0.71(0.10-1.29)$ & & $1.39(0.59-2.12)$ & & $0.39(-0.24$ to 1.01$)$ \\
\hline \multicolumn{7}{|l|}{$B D I-I I(0-63)$} \\
\hline Before treatment & 27 & $18.89 \pm 8.59$ & 27 & $18.30 \pm 6.67$ & 27 & $17.33 \pm 7.18$ \\
\hline After treatment & 23 & $9.35 \pm 5.57$ & 26 & $11.72 \pm 8.23$ & 26 & $13.60 \pm 8.57$ \\
\hline 3-month follow-up & 23 & $12.26 \pm 8.59$ & 16 & $7.69 \pm 4.59$ & 20 & $14.10 \pm 9.25$ \\
\hline Cohen’s d ${ }^{1}(95 \%$ CI) & & $1.32(0.66-1.93)$ & & $0.88(0.30-1.43)$ & & $0.47(-0.09$ to 1.02$)$ \\
\hline Cohen's d² (95\% CI) & & $0.77(0.17-1.36)$ & & $1.85(0.98-2.63)$ & & $0.39(-0.24$ to 1.01$)$ \\
\hline
\end{tabular}

By the time of the 18-month follow-up, the control group had received the same treatment as the ICBT group.

${ }^{1}$ Before vs. after treatment. ${ }^{2}$ Before treatment vs. 3-month follow-up. ${ }^{3}$ Before treatment vs. 18 -month follow-up.

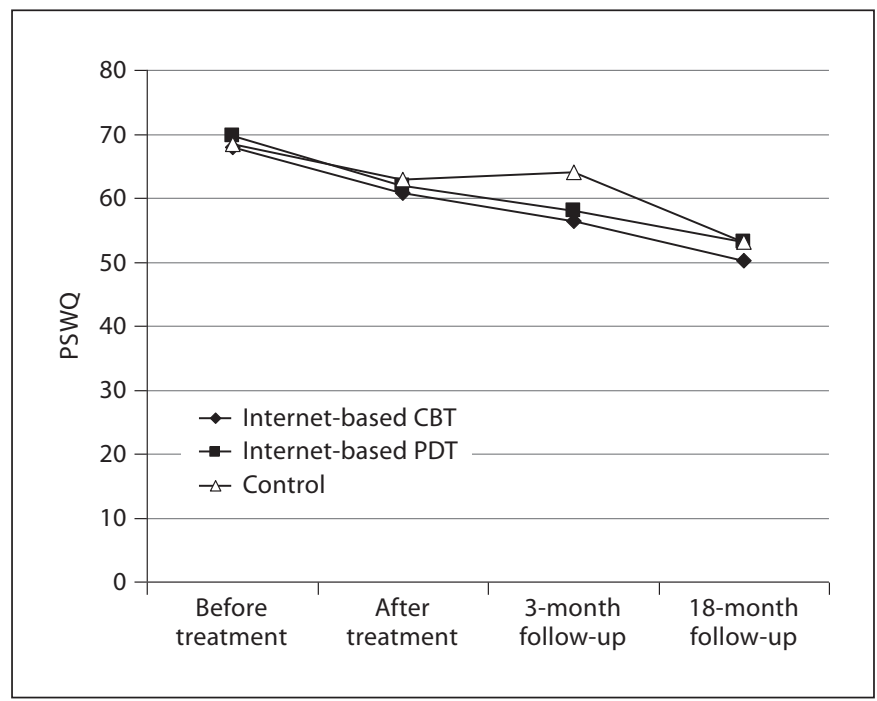

Fig. 2. PSWQ results at the four measurement occasions. The control group received treatment after the 3-month follow-up. For SDs, see table 3.

on the PSWQ, and regarding dropouts as non-responders, we found that the proportion of participants at 3 months who made a significant change was 8/27 (29.6\%; 95\% CI: $11.2-48.0 \%)$ for the PDT group, $12 / 27$ (44.4\%; 95\% CI: $24.4-64.5 \%)$ for the CBT group, and 2/27 (7.4\%;
95\% CI: -0.3 to $17.9 \%)$ for the waiting list control group. This difference was significant by means of $\chi^{2}=9.48, \mathrm{p}=$ 0.009 . On this primary measure, the difference between PDT and waiting list control group was significant, $\mathrm{p}=$ 0.04, as was the difference between CBT and the control condition, $\mathrm{p}=0.002$. The difference between the two treatments, PDT and CBT, was not significant; $\mathrm{p}=0.26$, all by $\chi^{2}$.

Mixed models (AR1) analysis with estimated means accounting for missing data and SDs for 81 participants was conducted for the pretreatment, posttreatment and 3 -month data points (estimated means available on request). This analysis did not reveal a significant time $\times$ treatment interaction $(\mathrm{p}=0.21)$.

In a second mixed models analysis (for estimated means see online table 2), we included the 18 -month follow-up data and excluded the waiting list control group data (table available on request). This revealed a significant effect of time $(\mathrm{p}<0.0001)$, but no interaction effect $(\mathrm{p}=0.94)$.

\section{Treatment Effectiveness - Secondary Outcome Measures}

Data from the secondary measures are provided in table 3 including within-group effect sizes. Data were analyzed in a similar manner as for the primary outcome measure. Again, between-group effects immediately after treatment were small and not significant. 
Table 4. Ratings of clinical CGI-I after treatment and at 18-month follow-up

\begin{tabular}{|c|c|c|c|c|c|c|}
\hline & \multicolumn{2}{|l|}{ ICBT } & \multicolumn{2}{|l|}{ IPDT } & \multicolumn{2}{|l|}{ Wait-list control } \\
\hline & $\begin{array}{l}\text { after treatment } \\
(\mathrm{n}=20), \%\end{array}$ & $\begin{array}{l}\text { 18-month } \\
\text { follow-up } \\
(\mathrm{n}=24), \%\end{array}$ & $\begin{array}{l}\text { after treatment } \\
(\mathrm{n}=22), \%\end{array}$ & $\begin{array}{l}\text { 18-month } \\
\text { follow-up } \\
(n=22), \%\end{array}$ & $\begin{array}{l}\text { after treatment } \\
(\mathrm{n}=25), \%\end{array}$ & $\begin{array}{l}\text { 18-month } \\
\text { follow-up } \\
(\mathrm{n}=21), \%\end{array}$ \\
\hline Very much improved & 35.0 & 16.7 & 4.5 & 4.5 & - & 14.3 \\
\hline Much improved & 10.0 & 50.0 & 36.4 & 45.5 & - & 42.9 \\
\hline Minimally improved & 35.0 & 16.7 & 31.8 & 31.8 & 32.0 & 28.6 \\
\hline No change & 10.0 & 12.5 & 22.7 & 13.6 & 48.0 & 9.5 \\
\hline Minimally worse & - & 4.2 & 4.5 & 4.5 & 8.0 & 4.8 \\
\hline Much worse & - & - & - & - & - & - \\
\hline Very much worse & - & - & - & - & - & - \\
\hline
\end{tabular}

For the GAD-Q-IV, the effect size between IPDT and the control condition was large at 3 months $(\mathrm{d}=1.14 ; 95 \%$ CI: $0.40-1.82)$, and similarly for the ICBT versus control condition ( $d=0.87 ; 95 \%$ CI: $0.23-1.48)$ at 3 months. The difference between the two treatments was small $(\mathrm{d}=$ -0.13 ; 95\% CI: -0.51 to 0.77 ) in favor of PDT. We found a significant interaction in the mixed models (AR1) analysis $(\mathrm{p}=0.003)$, with pairwise comparisons showing that the two active treatments were superior to the waiting list group. For the 18-month follow-up data, there was a significant time effect $(\mathrm{p}<0.0001)$, but no differences between IPDT and ICBT on this measure.

Data on self-reported MADRS-S showed large withingroup effect sizes (table 3). The between-group effect sizes showed a slight superiority at 3 months for IPDT versus the control condition ( $\mathrm{d}=0.68$; 95\% CI: $0.01-1.34)$, but no such between-group effect was seen for ICBT versus the control condition ( $\mathrm{d}=-0.18$; $95 \% \mathrm{CI}:-0.77$ to 0.43 ). IPDT was not better than the CBT condition at 3 months $(\mathrm{d}=-0.39 ; 95 \%$ CI: -0.22 to 0.99 ). Mixed models (AR1) analysis did not show an interaction at 3 months. For the 18-month data where PDT and CBT were compared, we found an interaction $(\mathrm{p}=0.02)$, with pairwise contrasts showing a difference in favor of ICBT at 18-month follow-up.

As a measure of quality of life, we used the QOLI. Within-group effect sizes varied, and the between-group effect sizes were nonsignificantly in favor of IPDT at 3 months ( $d=0.51,95 \%$ CI: -0.17 to 1.16 ) when compared with controls $(d=0.16,95 \%$ CI: $0.03-1.35)$ when compared with ICBT. CBT did not differ from the control condition at 3 months $(\mathrm{d}=0.15)$. Mixed models showed no interaction at 3 months, and when we analyzed the 18-month data, there were no interactions. There was however a within-group effect $(\mathrm{p}=0.007)$.
Data for the STAI-S, STAI-T, BAI and BDI largely overlapped with the other measures (i.e. GAD-Q-IV). Means and effect sizes including confidence intervals are presented in table 3. There was no statistical interaction on any of these measures.

\section{Clinical Global Functioning}

All available participants were assessed in a blinded interview at posttreatment and at 18-month follow-up. The distribution of the participants in terms of clinical global improvement from baseline is presented in table 4 . Given the small numbers in each group, it was not regarded feasible to test for statistical significance. As can be seen in table 4 , there were no major adverse effects in terms of participants getting much or very much worse.

\section{Diagnostic Status and Clinically Significant Change on Completers Data}

At posttreatment SCID interviews, the percentage of participants who still fulfilled the GAD diagnosis was $45.5 \%(10 / 22)$ for the IPDT group, $65.0 \%(13 / 20)$ for the ICBT group, and $84.0 \%(21 / 25)$ for the control condition $\left(\chi^{2}=7.72, \mathrm{p}=0.02\right)$. At 18 -month follow-up, this changed to $27.3 \%(6 / 22), 33.3 \%(6 / 24)$, and $38.1 \%(8 / 21)$ for the IPDT, ICBT and control condition, respectively (by which time the controls had received their CBT treatment). Table 5 displays the proportion of participants reaching the criteria of being clinically recovered - meaning that they had a reliable change and reached the 2 SD criterion of clinical significant improvement as defined by Jacobson and Truax [31]. 
Table 5. Proportion of participants considered clinically recovered (meaning that they had a reliable change and reached the 2 SD criterion of clinically significant improvement as defined by Jacobson and Truax [31])

\begin{tabular}{|c|c|c|c|c|c|c|}
\hline & \multicolumn{2}{|l|}{ ICBT } & \multicolumn{2}{|l|}{ IPDT } & \multicolumn{2}{|c|}{ Wait-list control } \\
\hline & $\mathrm{n} /$ total & $\%$ & $\mathrm{n} /$ total & $\%$ & $\mathrm{n} /$ total & $\%$ \\
\hline \multicolumn{7}{|l|}{ PSWQ } \\
\hline After treatment & $6 / 23$ & 26.1 & $4 / 26$ & 15.4 & $4 / 26$ & 15.4 \\
\hline 3-month follow-up & $12 / 23$ & 52.2 & $8 / 16$ & 50.0 & $2 / 20$ & 10.0 \\
\hline 18-month follow-up & $12 / 22$ & 54.5 & $15 / 22$ & 68.2 & $12 / 20$ & 60.0 \\
\hline \multicolumn{7}{|l|}{$G A D-Q I V$} \\
\hline After treatment & $8 / 23$ & 34.8 & $9 / 26$ & 34.6 & $11 / 26$ & 42.3 \\
\hline 3-month follow-up & $11 / 23$ & 47.8 & $11 / 16$ & 68.8 & $5 / 20$ & 25.0 \\
\hline 18-month follow-up & $22 / 22$ & 100.0 & $21 / 22$ & 95.5 & $19 / 20$ & 95.0 \\
\hline \multicolumn{7}{|l|}{ MADRS-S } \\
\hline After treatment & $10 / 23$ & 43.5 & $3 / 26$ & 11.5 & $4 / 26$ & 15.4 \\
\hline 3-month follow-up & $7 / 23$ & 30.4 & $5 / 16$ & 31.3 & $6 / 20$ & 30.0 \\
\hline 18-month follow-up & $13 / 22$ & 59.1 & $6 / 22$ & 27.3 & $10 / 20$ & 50.0 \\
\hline \multicolumn{7}{|l|}{ QOLI } \\
\hline After treatment & $0 / 23$ & 0.0 & $0 / 26$ & 0.0 & $0 / 26$ & 0.0 \\
\hline 3-month follow-up & $0 / 23$ & 0.0 & $1 / 16$ & 6.3 & $0 / 20$ & 0.0 \\
\hline 18-month follow-up & $1 / 22$ & 4.5 & $1 / 22$ & 4.5 & $0 / 20$ & 0.0 \\
\hline
\end{tabular}

By the time of the 18-month follow-up, the control group had received the same treatment as the ICBT. Completer data presented.

\section{Discussion}

The present study is probably the first to demonstrate that a psychodynamically informed guided self-help treatment can be delivered over the Internet, and that it can be as effective as ICBT-informed guided self-help in the treatment of GAD. Both treatments demonstrated moderate within-group effect sizes in the primary outcome measure of worry, but were only marginally better than the waiting list group at 3-month follow-up, and did not prove to be more effective when intention-to-treat analyses were conducted (mixed models). The overall finding was, however, that the two active treatments were similar in terms of outcome on both primary and secondary outcomes. The sample was self-recruited and displayed substantial comorbidity as is commonly seen in studies on GAD [2]. While a proportion of participants improved and maintained the improvement at 18 -month follow-up, there were other participants who remained symptomatic. There are several possible reasons for why robust changes were not found following the two active treatments. For example, it may be that our mainly textbased treatments are less suitable for GAD than other protocols in which more pictures are used [9]. On the oth- er hand, we used the same CBT treatment as in our previous GAD trial, which was found to be effective. It may also be that more therapist support is needed in IPDT, even if previous ICBT studies do not indicate that this would be the case [33] given that in the PDT model participant 'resistances' to moving through the tasks in each module could require more individually tailored discussion with the therapists. In addition, ways to foster and encourage participants towards module completion might also be considered.

The CBT arm of the present study replicates previous guided Internet trials on GAD in which ICBT had been found to be effective [7-9], with largely similar withingroup effect sizes on the PSWQ. All previous Internetbased trials have been based on CBT protocols with therapists that have, most likely, been less skilled (i.e. students) and less experienced than therapists in previous face-to-face trials on GAD [27] making comparisons to face-to-face GAD treatment studies difficult at this point.

Although the elements of the psychodynamic treatment tested in our trial can be found in the treatment tested in the trial by Leichsenring et al. [5] in terms of shared underlying psychodynamic principles, in the conduct of treatment there were clear differences due to the 
treatment's self-administered guided Internet delivery. By necessity, guided Internet-based treatment requires that the treatment be presented clearly in text making the therapist is less important. Moreover, treatment in the study by Leichsenring et al. [5] was based upon the manual by Crits-Christoph et al. [34] which was derived from Luborsky's Supportive-Expressive (S-E) short-term PDT [35]. Certainly, S-E treatment shares some similarities in underlying principles, especially the shared emphasis on gaining insight into a psychodynamic understanding that helps facilitate change as well as maintaining the psychodynamic principles that the patient's difficulties are perpetuated if such underlying dynamics remain hidden and, additionally, that the human mind, with its unconscious aspect can keep these dynamics hidden unless a properly guided investigation is conducted. However, in carrying out the methods, these two treatments have significant differences. The SUBGAP method is self-administered by means of the subject reading the modules of educational material and augmented via coaching the subject through the text, while the S-E method is very therapist driven. The S-E method is heavily dependent on the therapist's in-session interpretations to the subject, and is reliant on the transference relationship that happens in the therapy room as one focus for interpretation. In Internet-based treatments, the therapist is less important, and small to nonexistent therapist effects have been found [36]. However, in our trial, therapists were supervised by experienced clinicians and some therapeutic alliance, albeit at a distance, was formed between therapist and client, which is in line with previous Internet trials [37]. In addition, there was little overlap between the two treatments, as the PDT did not include any homework assignments, no relaxation, worry control or any typical CBT ingredients. One difference, however, was the fact that the IPDT therapists received more supervision with 7 sessions compared to 4 in the ICBT group. There is no research on the importance of supervision in ICBT, and since IPDT was a novel treatment for the therapists who participated, we assumed that more supervision would be needed. However, this is a potential systematic difference between the two treatments that also has implications for costs of delivering the treatment.

It may be interesting to note for the purposes of future investigation that, in one regard, there may be some overlap between psychodynamic and CBT procedures in general. In the PDT treatment, there was a focus on discovering unconscious patterns, on making the 'unconscious conscious' consistent with the cornerstones of psychodynamic theory, and through such insight and through un- derstanding a psychodynamic pattern's connection to a person's history (another way of discussing the 'repetition compulsion') and/or with his or her underlying emotions or motives, to initiate a change in such patterns. Similarly, in the CBT condition there was a focus on identifying and challenging habitual cycles of negative thought through the processes of cognitive restructuring and/or cognitive diffusion.

One could argue that the psychodynamic approach to recognizing and working through unproductive patterns and the cognitive behavioral approach to restructuring negative thoughts could be seen as sharing some similarities that stem back to the crossroads whereupon CBT was conceived, and could be reflective of the psychodynamic approaches in which some of the fathers of CBT were trained. Nevertheless, regardless of such philosophically overarching issues, it is probably safest to regard our present study as a proof-of-concept trial and recommend that the SUBGAP treatment, which represents the first wellmanualized and research-friendly form of psychodynamic self-guided treatment, needs to be tested further given the fact that the literature on Internet-based psychological treatment is dominated by CBT approaches [6].

This study has several limitations in addition to attempting to address the obvious question of whether or not PDT can be presented effectively over the Internet. First, although we did have a control group, it was not an active control group with a placebo condition (such as one that emulated the module model but did not deliver a treatment), the presence of which would have further enhanced the strength of the research design. Oddly, the waiting-list group did show some notable improvements during the waiting period, which may be related to the extensive test procedures both in terms of online questionnaires and telephone interviews before and after the treatment period and nonspecific helpful effects between interviewer and participant. However, in previous Internet trials on GAD control groups, participants did not improve at all during the waiting period $[7,8]$. In addition, as we offered treatment to the waiting list control group after the waiting period, we have no control group at the 18-month follow-up. Second, the dropout rate was substantial in the trial, and in particular the low response rate at 3-month follow-up for the PDT group limits the value of the findings. Third, the external validity of the findings remains as yet untested, as we recruited participants via newspaper advertisement rather than from a treatment clinic. There are prior studies showing that the effects of ICBT are generalizable to more customary clinical settings [38-40], but it is still an open question if this 
is the case for IPDT as well. For example, as seen in table 1 , in the present study, a large proportion of the participants had completed higher education following gymnasium (i.e. after 18 or 19 years of age). On the other hand, while not recruited from a clinical setting, the sample recruited in this present study was certainly characterized by a high level of comorbidity and showed scores on the symptom-specific measures that did not indicate a lower level of distress than would be expected from a sample recruited in a clinical setting.

In conclusion, this study opens up treatment possibilities and accessibility by suggesting that psychodynamic treatment approaches may be transferred to the guided self-help format and delivered via the Internet.

\section{Acknowledgements}

This study was supported by a research grant from the Swedish council for working and life research (Dr. Andersson). We wish to express our great appreciation of the important work done by the following persons: Stina Airola von Scherling, Oskar Eriksson, Emil Holmer and Mattias Holmqvist Larsson for working as Internet therapists, and Andreas Rosseau (MD, $\mathrm{PhD}$ ) for serving as back-up regarding diagnostic issues and medication.

\section{References}

1 American Psychiatric Association: Diagnostic and Statistical Manual of Mental Disorders, ed 4, text revision. Washington, American Psychiatric Press, 2000.

-2 Tyrer P, Baldwin D: Generalised anxiety disorder. Lancet 2006;368:2156-2166.

73 Mitte K: Meta-analysis of cognitive-behavioral treatments for generalized anxiety disorder: a comparison with pharmacotherapy. Psychol Bull 2005;131:785-795.

4 Crits-Christoph PE, Connoly MB, Azarin K, Crits-Christoph K, Shappel S: An open trial of brief supportive-expressive psychotherapy in the treatment of generalized anxiety disorder. Psychotherapy 1996;33:418-430.

$\checkmark 5$ Leichsenring F, Salzer S, Jaeger U, Kachele H, Kreische R, Leweke F, et al: Short-term psychodynamic psychotherapy and cognitivebehavioral therapy in generalized anxiety disorder: a randomized, controlled trial. Am J Psychiatry 2009;166:875-881.

-6 Andersson G: Using the internet to provide cognitive behaviour therapy. Behav Res Ther 2009;47:175-180.

-7 Paxling B, Almlöv J, Dahlin M, Carlbring P, Breitholtz E, Eriksson T, et al: Internet-delivered cognitive behaviour therapy for generalized anxiety disorder. A randomized controlled trial. Cogn Behav Ther 2011;40:159173.

8 Titov N, Andrews G, Robinson E, Schwencke G, Johnston L, Solley K, et al: Clinician-assisted Internet-based treatment is effective for generalized anxiety disorder: randomized controlled trial. Aust N Z J Psychiatry 2009;43:905-912.

-9 Robinson E, Titov N, Andrews G, McIntyre $\mathrm{K}$, Schwencke G, Solley K: Internet treatment for generalized anxiety disorder: a randomized controlled trial comparing clinician vs. technician assistance. PLoS One 2010; 5:e10942.
10 Andrews G, Cuijpers P, Craske MG, McEvoy $\mathrm{P}$, Titov N: Computer therapy for the anxiety and depressive disorders is effective, acceptable and practical health care: a meta-analysis. PLoS One 2010;5:e13196.

11 First MB, Gibbon M, Spitzer RL, Williams JBW: Structured Clinical Interview for DSM-IV Axis I Disorders (SCID-I). Washington, American Psychiatric Press, 1997.

-12 Cacciola JS, Alterman AI, Rutherford MJ, McKay JR, May DJ: Comparability of telephone and in-person structured clinical interview for DSM-III-R (SCID) diagnoses. Assessment 1999;6:235-242.

13 Meyer TJ, Miller ML, Metzger RL, Borkovec TD: Development and validation of the Penn State Worry Questionnaire. Behav Res Ther 1990;28:487-495.

14 Fresco DM, Mennin DS, Heimberg RG, Turk CL: Using the Penn State Worry Questionnaire to identify individuals with generalized anxiety disorder: a receiver operating characteristic analysis. J Behav Ther Exp Psychiatry 2003;34:283-291.

15 Newman MG, Zuellig AR, Kachin KE, Constantino MJ, Przeworski A, Erickson T, et al: Preliminary reliability and validity of the GAD-Q-IV: A revised self-report diagnostic measure of generalized anxiety disorder. Behav Ther 2002;33:215-233.

16 Newman MG, Zuellig AR, Kachin KE, Constantino MJ, Przeworski A, Erickson T, et al: Preliminary reliability and validity of the GAD-Q-IV: a revised self-report diagnostic measure of generalized anxiety disorder. Behav Ther 2002;33:215-233.

17 Svanborg P, Åsberg M: A comparison between the Beck Depression Inventory (BDI) and the self-rating version of the Montgomery Asberg Depression Rating Scale (MADRS). J Affect Disord 2001;64:203-216.
18 Snaith RP, Harrop FM, Newby DA, Teale C: Grade scores of the Montgomery-Asberg Depression and the Clinical Anxiety Scales. Br J Psychiatry 1986;148:599-601.

19 Frisch MB, Cornell J, Villanueva M, Retzlaff PJ: Clinical validation of the Quality of Life Inventory: a measure of life satisfaction for use in treatment planning and outcome assessment. Psychol Assess 1992;4:92-101.

20 Spielberger CD, Gorsuch RL, Lushene R: Test Manual for the State-Trait Anxiety Inventory. Palo Alto, Consulting Psychologists Press, 1970.

21 Beck AT, Steer RA, Brown GK: Manual for the Beck Depression Inventory-II. San Antonio, Psychological Corporation, 1996.

22 Beck AT, Epstein N, Brown G, Steer R: An inventory for measuring clinical anxiety. Psychometric properties. J Consult Clin Psychol 1988;56:893-897.

23 Holländare F, Andersson G, Engström I: A comparison of psychometric properties between Internet and paper versions of two depression instruments (BDI-II and MADRSS) administered to clinic patients. JMIR 2010;12:e49.

24 Guy W: Clinical Global Impressions. ECDEU Manual, US Dept of Health and Human Services. Rockville, NIMH, 1976, pp 217-222.

25 Silverberg F: Make the Leap. A Practical Guide to Breaking the Patterns That Hold You Back. New York, Marlowe and Company, 2005.

26 Öst L-G: Applied relaxation: description of a coping technique and review of controlled studies. Behav Res Ther 1987;25:379-409.

27 Borkovec TD, Newman MG, Pincus AL, Lytle R: A component analysis of cognitive-behavioral therapy for generalized anxiety disorder and the role of interpersonal problems. J Consult Clin Psychol 2002;70:288-298. 
28 Gueorguieva R, Krystal JH: Move over ANOVA: progress in analyzing repeatedmeasures data and its reflection in papers published in the Archives of General Psychiatry. Arch Gen Psychiatry 2004;61:310-317.

29 Brown H, Prescott R: Applied Mixed Models in Medicine. New York, Oxford University Press, 1999.

30 Cohen J: Statistical Power Analysis for the Behavioral Sciences, ed 2. Hillsdale, Lawrence Erlbaum Associates, 1988.

-31 Jacobson NS, Truax P: Clinical significance: a statistical approach to defining meaningful change in psychotherapy research. J Consult Clin Psychol 1991;59:12-19.

-32 Piaggio G, Elbourne DR, Altman DG, Pocock SJ, Evans SJ: Reporting of noninferiority and equivalence randomized trials: an extension of the CONSORT statement. JAMA 2006;295:1152-1160.
33 Palmqvist B, Carlbring P, Andersson G: Internet-delivered treatments with or without therapist input: does the therapist factor have implications for efficacy and cost? Expert Rev Neurother 2007;7:291-297.

34 Crits-Christoph P, Connolly Gibbons MB, Crits-Christoph K: Supportive-expressive psychodynamic therapy; in Heimberg RG Turk CL, Mennin DS (eds): Generalized Anxiety Disorder: Advances in Research and Practice. New York, Guilford Press, 2004, pp 293-319.

35 Luborsky L: Principles of Psychoanalytic Psychotherapy: A Manual for SupportiveExpressive Treatment. New York, Basic Books, 1984.

36 Almlöv J, Carlbring P, Källqvist K, Paxling B, Cuijpers P, Andersson G: Therapist effects in guided Internet-delivered CBT for anxiety disorders. Behav Cogn Psychother 2011;39: 311-322.
37 Knaevelsrud C, Maercker A: Internet-based treatment for PTSD reduces distress and facilitates the development of a strong therapeutic alliance: a randomized controlled clinical trial. BMC Psychiatry 2007;7:13.

38 Bergström J, Andersson G, Ljótsson B, Rück C, Andréewitch S, Karlsson A, et al: Internetversus group-administered cognitive behaviour therapy for panic disorder in a psychiatric setting: a randomised trial. BMC Psychiatry 2010;10:54.

-39 Bergström J, Andersson G, Karlsson A, Andreewitch S, Rück C, Carlbring P, et al: An open study of the effectiveness of Internet treatment for panic disorder delivered in a psychiatric setting. Nord J Psychiatry 2009; 63:44-50.

40 Aydos L, Titov N, Andrews G: Shyness 5: the clinical effectiveness of Internet-based clinician-assisted treatment of social phobia. Australas Psychiatry 2009;17:488-492. 